TITLE:

\title{
Kinetics on the oxidation of biodiesel stabilized with antioxidant
}

$\operatorname{AUTHOR}(S)$ :

Xin, Jiayu; Imahara, Hiroaki; Saka, Shiro

CITATION:

Xin, Jiayu ...[et al]. Kinetics on the oxidation of biodiesel stabilized with antioxidant. Fuel 2009, 88(2): 282-286

ISSUE DATE:

2009-02

URL:

http://hdl.handle.net/2433/87778

RIGHT:

c 2009 Elsevier Ltd. All rights reserved; この論文は出版社版でありませ ん。引用の際には出版社版をご確認ご利用ください。; This is not the published version. Please cite only the published version. 


\title{
Kinetics on the Oxidation of Biodiesel Stabilized with Antioxidant
}

\author{
Jiayu Xin, Hiroaki Imahara, Shiro Saka \\ Graduate School of Energy Science, Kyoto University, Kyoto, Japan \\ Yoshida-honmachi, Sakyo-ku, Kyoto 606-8501, Japan
}

Corresponding author, Tel: +81-75-753-4738; Fax: +81-75-753-4738. E-mail address:

saka@energy.kyoto-u.ac.jp (S. Saka). 


\section{Abstract}

Oxidation stability of safflower biodiesel stabilized with propyl gallate whose concentration spreads from $0-5,000 \mathrm{ppm}$ was studied by Rancimat method at temperatures from $100-120^{\circ} \mathrm{C}$. It was consequently demonstrated that the induction period of biodiesel increases with the increase of antioxidant concentration and decreases with increase of temperature. Kinetics on its oxidation was described by the first order rate law with an accuracy higher than 0.98 . The reaction rate of propyl gallate consumed in safflower biodiesel obtained from the experiment fits well with Arrhenius equation and the activation energy obtained from Arrhenius equation was $97.02 \mathrm{~kJ} / \mathrm{mol}$. Logarithm of induction periods determined by Rancimat method with various antioxidant concentrations shows a linear relation with temperatures. It was, consequently, found that the Rancimat method for the oxidation stability determination shows an approximate correlation between storage stability and Rancimat induction period. The Rancimat method cannot directly measure the overall storage stability of fuels, since other conditions such as presence of water, microbial contamination, storages conditions etc. would affect fuel quality during storage.

Keywords: kinetics; biodiesel; oxidation stability; antioxidant; propyl gallate 


\section{Introduction}

Biodiesel consists of long-chain fatty acid methyl esters (FAME) obtained from vegetable oils such as rapeseed oil, palm oil, soybean oil, sunflower oil, peanut oil, as well as animal fats and used cooking oils [1-3], which are renewable and their utilization is carbon-neutral and low exhaust emission. With the increase of environment protection consciousness and decrease of petroleum reserves, more and more biodiesel is being used in many countries such as Germany, France, Italy, USA and so on. It was, therefore, reported that production capacity of biodiesel in EU in 2006 was 6,069,000 tones, and this value will reach 10,000,000 tones by 2010 [4].

However, biodiesel has lower oxidation stability compared with petroleum diesel because biodiesel has high content of unsaturated methyl esters, especially poly-unsaturated methyl esters easily oxidized such as methyl linoleate $\left(\mathrm{C}_{18: 2}\right)$ and methyl linolenate $\left(\mathrm{C}_{18: 3}\right)$, which lead to the formation of decomposed compounds such as acids, aldehydes, esters, ketones, peroxides and alcohols. These products not only affect the properties of biodiesel, but also bring the problems of engine operation [5]. As a result, the European Committee for Standardization established a standard (EN 14214) for biodiesel in 2003, which requires that biodiesel must reach a minimum induction period of $6 \mathrm{~h}$ as tested by Rancimat method at $110^{\circ} \mathrm{C}$.

Many researchers have paid attentions on the factors that affect the oxidation stability of biodiesel [6-15]. It was, then, found that, kinematic viscosity, acid value, ester content and peroxide value of biodiesel deteriorate along with oxidation time, at the end of Rancimat induction period, and that all of these parameters could not meet specification of the FAME or oils and fats. 
At the same time, the other research theme, prolonging the induction period of biodiesel by adding the antioxidant seems to be promising, which ensures high biodiesel oxidation stability. The effect of synthetic antioxidants such as pyrogallol, 3,4,5-trihydroxybenzoic acid propyl ester (propyl gallate), tert-butyl hydroquinone, tert-butyl hydroxyanisole, tert-butyl methyl-phenol and so on as well as natural antioxidants (tocopherols) has been studied on enhancing oxidation stability of biodiesel [16-19]. The results show that easily oxidized biodiesel can reach the oxidation stability specification by adding the antioxidant. The stability of biodiesel enhanced by adding the antioxidant has been widely studied, but on the kinetics of oxidation has not been reported yet.

Therefore, the purpose of this study was to establish an oxidation reaction law of the antioxidant preventing oxidation of biodiesel. Rancimat method test which can accelerate oxidation was carried out for safflower biodiesel stabilized with propyl gallate at various temperatures. Furthermore, the Rancimat method for long term storage stability of biodiesel determination was also evaluated.

\section{Materials and Methods}

\subsection{Materials}

To obtain induction period readily and study the effect of antioxidant on stabilizing biodiesel in a wide range, susceptibly oxidized biodiesel that has poor oxidation stability and high unsaturated methyl ester content is a good candidate. Thus the safflower biodiesel was used in this study, which was prepared by alkali-catalyzed method [20] from safflower oil (Nacalai Tesque; Kyoto, Japan). Key properties of safflower biodiesel and European specification standard are 
shown in Table 1. Palm and rapeseed biodiesel were also prepared by alkali-catalyzed method from palm oil and rapeseed oil (Nacalai Tesquel; Kyoto, Japan).

In our previous experiment, one of the most widely used antioxidant, butylated hydroxytoluene (BHT) was found to have high vapor pressure, thus a part of BHT vaporized at high temperature. To avoid a change of the antioxidant concentration due to vaporization, propyl gallate was used as antioxidant. As a chain-breaking radical scavenging antioxidant, propyl gallate is widely used in food, petroleum chemistry and polymer [21]. Propyl gallate was purchased from Sigma, Japan.

Standard free fatty acid methyl esters such as methyl palmitate $\left(\mathrm{C}_{16: 0}\right)$, methyl stearate $\left(\mathrm{C}_{18: 0}\right)$, methyl oleate $\left(\mathrm{C}_{18: 1}\right)$, methyl linoleate $\left(\mathrm{C}_{18: 2}\right)$ and methyl linolenate $\left(\mathrm{C}_{18: 3}\right)$ were purchased from Nacalai Tesque Inc., Japan as standards whit their purities being higher than 99\%. $\alpha$-tocopherol, $\beta$-tocopherol and $\gamma$-tocopherol were bought from Supelco. Inc., Bellefonte, Pennsylvania, USA.

\subsection{Methods}

Oxidation stability of safflower biodiesel samples with different antioxidant blends was studied according to EN 14112 [22] in Rancimat equipment model 743 (Metrohm, Herisau, Switzerland), which was operated under the following conditions: air flow rate, $10 \mathrm{~L} / \mathrm{h}, 3 \mathrm{~g}$ biodiesel sample was placed at a heating block with temperature set from $100-120^{\circ} \mathrm{C}$, the vapors discharged to a flask containing $0.06 \mathrm{~L}$ distilled water and the conductivity change was recorded by a computer simultaneously. The induction periods of biodiesel samples with antioxidant concentrations from 0-5,000ppm were determined. 
The chemical composition of safflower biodiesel was determined by a high-performance liquid chromatography (HPLC) (Shimadzu, LC-10AT) which consists of the column (Cadenza CD-C18, $25 \mathrm{~cm}$ in length $\times 4.6 \mathrm{~mm}$ in inner diameter, Imtakt Co.) and refractive index detector (Shimadzu, RID-10A) operated at $40{ }^{\circ} \mathrm{C}$ with $1.0 \mathrm{~mL} / \mathrm{min}$ flow rate of methanol as a carrier solvent, and the peak identification was made by comparing the retention time between the sample and the standard compound. Tocopherol content was also determined by the HPLC with the column (Asahipak ODP-50 6D, $15 \mathrm{~cm}$ in inner length $\times 6 \mathrm{~mm}$ diameter, Shodex Co.) and fluorescence detection (excitation 298nm, emission 325nm, RF-10AXL, Shimadzu) operated at $30{ }^{\circ} \mathrm{C}$ with $1.0 \mathrm{~mL} / \mathrm{min}$ flow rate of methanol as a carrier solvent, and the peak identification was made by comparing the retention time between the sample and the standard compound.

\section{Results and Discussion}

\subsection{Composition and natural antioxidant content of safflower biodiesel}

Safflower biodiesel contains 89.1\% unsaturated methyl esters $\left(\mathrm{C}_{18: 1}, \mathrm{C}_{18: 2}, \mathrm{C}_{18: 3}\right)$. As we know that the oxidation stability of unsaturated methyl esters decreases according to the order of $\mathrm{C}_{18: 3 \text {, }}$ $\mathrm{C}_{18: 2,} \mathrm{C}_{18: 1}$, and its relative rates reported in the literature [23] are 1 for $\mathrm{C}_{18: 1}, 41$ for $\mathrm{C}_{18: 2}$ and 98 for $\mathrm{C}_{18: 3}$. However, safflower biodiesel contains 104ppm tocopherol (78ppm $\alpha$-tocopherol, 3ppm $\beta$-tocopherol and 23ppm $\gamma$-tocopherol) as a natural antioxidant. Therefore, it affects oxidation stability of the biodiesel, because of lower natural antioxidant content and high unsaturated ester composition, the induction period of safflower biodiesel is only $0.86 \mathrm{~h}$, which is far below the specification of EN14112 to satisfy the requirements. Therefore, additional antioxidant to the 
biodiesel is inevitable.

\subsection{Effect of temperature and antioxidant concentration on oxidation stability}

Figure 1 shows the influence of antioxidant concentration on the oxidation stability of safflower biodiesel for the test temperatures as set at $100,105,110,115$ and $120^{\circ} \mathrm{C}$. We can see clearly that the higher the temperature, the shorter the induction period. In addition, the higher the propyl gallate concentration, the longer the induction periods. The effect of propyl gallate concentration on the induction period is more evident when the antioxidant concentration is less than 1,000ppm. Changes of induction period with the concentration of propyl gallate can be illustrated by the slop of the curve. With the increase of propyl gallate concentration, the slope becomes smaller.

\subsection{Kinetics on oxidation of biodiesel as stabilized with propyl gallate}

Oxidation reaction of organic compound is a chain reaction process and rather complicated, consisting of numerous elementary steps [24]. The process is an autoxidation process if chain propagation reaction is faster than chain termination; if the antioxidant is active and its concentration is high enough, chain propagation will be broken through the reaction of transfer hydrogen atom from antioxidant to intermediate peroxyl radicals [25].

The curves in Fig. 1 appear to be nonlinear and, possible, be exponential logarithm function, as we know the first order reaction kinetics may be used to describe its mechanism. Antioxidant in 
biodiesel plays an important role in determining length of induction period. At the beginning of Rancimat test, the concentration of propyl gallate is $C_{0}$. With the increase of oxidation time, concentration of propyl gallate decreases and the end of induction period, its concentration becomes to be $C_{c r}$. The $C_{c r}$ refers to the concentration of propyl gallate below such value to have no effect on retarding the oxidation of biodiesel. Therefore the rate of consumption of antioxidant is considered on the basis of the kinetics of the first order reaction for which the rate equations is:

$$
\begin{aligned}
\frac{d c}{d t} & =-k \cdot c \\
\text { or } \quad \frac{d c}{c} & =-k d t
\end{aligned}
$$

where $c$ is the concentration of propyl gallate, $C_{0}$ and $C_{c r}$ are the initial and critical concentrations of the antioxidant in biodiesel, $t_{i}$ is the induction period tested by Rancimat method, while $k$ is the reaction constant of propyl gallate consumption.

Integration of equation (1) within the concentration range from $C_{0}$ to $C_{c r}$ and time limits $t=t_{i 0}$ to $t=t_{i}$ results in the dependence of rate constants of antioxidant consumption on the concentration and time shown in equation (2):

$$
\begin{gathered}
-\int_{C_{0}}^{C_{c r}} \frac{d c}{c}=\int_{t_{i 0}}^{t i} k d t \\
\ln C_{0}-\ln C_{c r}=k t_{i}-k t_{i 0}
\end{gathered}
$$

where $t_{i 0}$ means the induction period tested by Ranciamt method for biodiesel without synthetic antioxidant addition. As mentioned before, when the antioxidant concentration is below $C_{c r}$, the induction period is equal to that without synthetic antioxidant, $t_{i 0}$. Therefore, (2) can be written as follows:

$$
t_{i}=\frac{1}{k} \ln \frac{C_{0}}{C_{c r}}+t_{i 0}
$$




$$
\ln C_{0}=k\left(t_{i}-t_{i 0}\right)+\ln C_{c r}
$$

This shows a linear relation between initial concentration of antioxidant $C_{0}$ and induction period $t_{i}$. The term $t_{i}-t_{i 0}$ is means the change in induction period after adding antioxidant relative to no added antioxidant.

Figure 2 shows dependence of the induction period of safflower biodiesel on the Napierian (natural) logarithm (ln) of propyl gallate concentration at 100, 105, 110, 115 and $120{ }^{\circ} \mathrm{C}$. Straight lines were determined to fit the data in order to adopt the first order rate equation. As expected, the lines show a high degree of correlation, and as shown in Table 2, all coefficients exceed 0.98.

Critical concentration $C_{c r}$, of propyl gallate can be determined by extrapolating the straight line to the induction period that without adding propyl gallate. Reaction constant $k$ shown in Table 2 at various temperatures equals to the slope of straight line. As it is shown that reaction constants increase with the temperature, which is 5 times larger at $120^{\circ} \mathrm{C}$ than $100{ }^{\circ} \mathrm{C}$. Higher reaction constant at higher temperature leads to faster antioxidant consumption rate and shorter induction period.

The reaction constant $k$ equals to the slop of the line in Fig. 2. In order to check whether the values of reaction constant $k$ calculated from Fig. 2 satisfy the Arrhenius equation describing the temperature dependence of the reaction rate constant, the graph of $\operatorname{lnk}$ versus $T^{1}$ was obtained for propyl gallate as shown in Fig. 3 based on the following equation:

$$
\begin{array}{r}
\ln k=-\frac{E_{a}}{R T}+B \\
\text { or } \quad k=A \exp \left(-\frac{E_{a}}{R T}\right)
\end{array}
$$

where $E a$ is activation energy, $R$ is ideal gas law constant $(8.314 \mathrm{~J} / \mathrm{mol} \cdot \mathrm{K}), B$ is constant that intercepts the straight line to vertical axis, A is the pre-exponential factor. 
The data obtained from experiment agreed very well with Arrhenius law. The activation energy calculated for propyl gallate consumption is $E_{a}=97.02 \mathrm{~kJ} / \mathrm{mol}$. Activation energy indicates the degree of temperature-sensitiveness; reactions with high activation energies are very temperature-sensitive while reactions with low activation energies are low in temperature-sensitiveness. The activation energies of most reactions spread from 40-400kJ/mol [26]. It indicates that propyl gallate consumed in safflower biodiesel is relatively low temperature-sensitiveness at the experiment temperature, but we can not draw a safe conclusion that the temperature-sensitive is high or low at a ambient temperature because any given reaction is much more temperature-sensitive at a low temperature than a high temperature.

\subsection{Induction period as obtained by extrapolated method}

Figure 4 shows logarithm of induction period as a function of temperature for safflower biodiesel stabilized with various concentrations of propyl gallate. Interestingly, induction period and temperature are a highly linear-correlated. Hasenhuettl [27] has found a linear relation between induction period and temperature of triglycerides without using synthetic antioxidant. If the consumption mechanism of synthetic antioxidant in biodiesel does not change at the ambient temperature, the straight lines in Fig. 4 can be extrapolated to the lower temperature to get induction period at room temperature or any other temperatures of realistic storage conditions.

Figure 5 shows the result of the induction period (Stabilized time) as obtained by the extrapolated method. As shown, about 1,000ppm propyl gallate can guarantee one year storage at $25{ }^{\circ} \mathrm{C}$ without obvious degradation, which can be regarded as a more than realistic time span for 
the commercial life of biodiesel [8]; and about 400ppm propyl gallate can guarantee a half year storage for biodiesel without obvious degradation, which is thought to be the maximum commercial life of biodiesel under common market conditions [8]. Same as in Fig. 1, from the curve of induction period changes with antioxidant concentration in Fig. 5, it is clearly demonstrated that the antioxidant has a much significant effect at lower concentration. Approximate 400ppm is the concentration of induction period of 6h determined by Rancimat method at $110{ }^{\circ} \mathrm{C}$, for the biodiesel used in this study. Therefore, it satisfied the requirement of EN14112 standard.

During the initial stage in the oxidation of oil and lipid derivatives, the chain reactions are suppressed by chain breaking agents, for example antioxidants. This stage is defined as the induction period. Following the induction period, oxidation reactions proceed, decomposition of primary oxidation products (hydroperoxides) yield a mixture of secondary products including short-chain carboxylic acids, ketones, aldehydes, mono-and dihydroxy compounds and also polymers or sediments [28]. As a result, after induction period, not only the key properties of biodiesel degrade quickly, but also engine operation problems come forth. As the length of induction period is important for the commercial life of biodiesel, longer induction period tested in Rancimat test presents a longer tolerable storage time. Lacoste [14] found that evolution curves of quality parameters of biodiesel, such as ester content, kinematic viscosity at $40{ }^{\circ} \mathrm{C}$, polymer content and acid value, showed an inflexion point along Rancimat test. In the case of safflower biodiesel used in this study, the specification of EN14112 requires an induction period of $6 \mathrm{~h}$ at 110 ${ }^{\circ} \mathrm{C}$, which represents a stable storage time of a half year, one year stable storage time for induction period tested by Rancimat method at $110{ }^{\circ} \mathrm{C}$ is about $8 \mathrm{~h}$. 
In order to check whether the biodiesels having the same induction periods at $110{ }^{\circ} \mathrm{C}$ have the same induction periods at other temperatures, several biodiesel samples were prepared and their induction periods at various temperatures were determined. As expected, induction periods increase with decreasing temperature, when induction period plotted on a natural logarithmic scale against temperature (Fig. 6), where a straight line was obtained for the three biodiesel samples. The slopes of the lines in Fig. 6 represent the temperature coefficients for the natural logarithms of the induction period. Intercepts of lines shown in Fig. 6 represent even the biodiesels having the same induction period at $110^{\circ} \mathrm{C}$, but their long time storage stabilities are different. As a result, the Rancimat method only gives us approximate information about the stability of biodiesel and long induction period does not necessarily represent the long storage stability because of temperature coefficients are different among different biodiesels.

\section{Conclusions}

In a wide range of concentration of propyl gallate as antioxidant from 250 to 5,000ppm and temperatures from 100 to $120{ }^{\circ} \mathrm{C}$, the process of oxidation of safflower biodiesel could be described with a high accuracy by the first order kinetic law. Temperature and concentration of the antioxidant were found to act the negative and positive effects on the oxidation stability of biodiesel. The results obtained in this work suggested that biodiesel fuel stored at lower temperature is favorable for long time storage of biodiesel without degradation. Since the storage conditions such as presence of water, microbial contamination, storages conditions etc. could greatly affect the storage stability of biodiesel, but the extrapolating method gives a useful method 
to describing stabilized time at lower temperature.

\section{Nomenclature:}

$c$ : concentration of propyl gallate

$C_{0}$ : initial concentration of the antioxidant in biodiesel

$C_{c r}$ : critical concentration of the antioxidant in biodiesel

$t_{i}$ : induction period tested by Rancimat method

$k$ : the reaction constant of propyl gallate consumption

$t_{i 0}$ : induction period tested by Ranciamt method for biodiesel without synthetic antioxidant addition

Ea: activation energy

$R$ : ideal gas law constant $(8.314 \mathrm{~J} / \mathrm{mol} \cdot \mathrm{K})$

$B$ : constant that intercepts the straight line to vertical axis

A: pre-exponential factor.

\section{References}

[1] Ma F, Hanna MA. Biodiesel production: a review. Bioresource Technology, 1999; 70: 1-15

[2] Issariyakul T, Kulkarni MG, Dalai AK, Bakhshi NN. Production of biodiesel from waste fryer grease using mixed methanol/ethanol system. Fuel Processing Technology, 2007; 88: 429-436

[3] He H, Wang T, Zhu S. Continuous production of biodiesel fuel from vegetable oil using supercritical methanol process. Fuel, 2007; 86: 442-447

[4] http://www.ebb-eu.org/stats.php

[5] Monyem A, Van Gerpen JH. The effect of biodiesel oxidation on engine performance and 
emissions. Biomass and Bioenergy, 2001; 20: 317-325

[6] Plessis LM, Villiers JBM and Walt WV. Stability studies on methyl and ethyl fatty acid esters of sunflowerseed oil. JAOCS, 1985; 62: 748-752

[7] Bondioli P, Gasparoli A, Lanzani A, Fedeli E, Veronese S and Sala M. Storage stability of biodiesel. JAOCS, 1995; 72: 699-702

[8] Bondioli P, Gasparoli A, Bella L, Tagliabue S, Toso G. Biodiesel stability under commercial storage conditions over one year. European Journal of Lipid Science and Technology, 2003; 105: 735-741

[9] Mittelbach M, Gangl S. Long storage stability of biodiesel made from rapeseed and frying oil. JAOCS, 2001; 78:573-577

[10] Bouaid A, Martinez M, Aracil J. Long storage stability of biodiesel from vegetable and used frying oils, Fuel, 2007; 86: 2596-2602

[11] Dunn RO. Effect of oxidation under accelerated conditions on fuel properties of methyl soyate (biodiesel) JAOCS, 2002; 79: 910-915

[12] Xin J, Imahara H, Saka S. Oxidation stability of biodiesel fuel as prepared by supercritical methanol, Fuel, 2008; 87: 1807-1813

[13] McCormick RL, Ratcliff M, Moens L. Several factors affecting the stability of biodiesel in standard accelerated tests. Fuel processing Technology, 2007; 88: 651-657

[14] Lacoste F, Lagardere L. Quality parameters evolution during biodiesel oxidation using Rancimat test. European Journal of Lipid Science and Technology, 2003; 105:149-155

[15] Bondioli P, Gasparoli A, Bella LD, Tagliabue S. Evaluation of biodiesel storage stability using reference methods. European Journal of Lipid Science and Technology, 2002; 
104:777-784

[16] Mittelbach M, Gangl S. The influence of antioxidants on the oxidation stability of biodiesel. JAOCS, 2003; 80: 817-823

[17] Liang YC, May CY, Foon CS, Ngan MA, Hock CC, Basiron Y. The effect of natural and synthetic antioxidants on the oxidative stability of palm diesel. Fuel, 2006; 85: 867-870

[18] Gangl S, Mittelbach M. The impact of antioxidants on biodiesel oxidation stability. European Journal of Lipid Science and Technology, 2004; 106: 382-389

[19] Dunn RO. Effect of antioxidants on the oxidative stability of methyl soyate (biodiesel). Fuel processing Technology, 2005; 86: 1071-1085

[20] Kusdiana D, Saka S. Effects of water on biodiesel fuel production by supercritical methanol treatment. Bioresource Technology, 1004; 91: 289-295

[21] Scott G. Antioxidants. The Chemical Society of Japan, 1988; 61: 165-170

[22] EN 14112, Determination of oxidation stability (accelerated oxidation test), European Committee for Standardization, Berlin, 2003

[23] Frankel E. Lipid Oxidation, The Oily Press, Dundee, Scotland, 1998

[24] Denisov ET, Khudyakov IV. Mechanisms of Action and Reactivities of the Free Radicals of Inhibitors. Chemical Reviews. 1987; 87: 1313-1357

[25] Porter NA. Mechanisms for the Autoxidation of Polyunsaturated Lipids. Accounts Chemical Research, 1986; 19: 262-268

[26] Levenspiel O. Chemical Reaction Engineering 3rd edition. John Wiley \& Sons Inc., New York. 27-29

[27] Hasenhuteel GL, Wan PJ. Temperature effects on the determination of oxidative stability with 
the Metrohm Rancimat. JAOCS, 1992; 69: 525-527

[28] Gan LH, Ooi KS, Gan LM, Goh SH. Effects of epoxidation on the thermal oxidative stabilities of fatty acid esters derived from palm olein. JAOCS, 1995;72: 439-442 
Table 1 Key properties of safflower biodiesel and European specification standard (EN14214)

\begin{tabular}{lcccc}
\hline Properties & Method & Unit & EN14214 & value \\
\hline Density at $15^{\circ} \mathrm{C}$ & EN ISO 3675 & $\mathrm{~g} / \mathrm{cm}^{3}$ & $0.86 \sim$ & 0.89 \\
Viscosity at $40^{\circ} \mathrm{C}$ & EN ISO 3104 & $\mathrm{~mm}^{2} / \mathrm{s}$ & $3.5 \sim 5.0$ & 4.1 \\
Pour point & ISO 3016 & ${ }^{\circ} \mathrm{C}$ & - & -7.5 \\
Cloud point & ISO 3105 & $\mathrm{o}$ & - & -5 \\
Ester content & $\mathrm{EN} 14103$ & $\mathrm{wt} \%$ & $>96.5$ & 97.8 \\
Monoglyceride & $\mathrm{EN} 14105$ & $\mathrm{wt} \%$ & $<0.8$ & 0.5 \\
Diglyceride & $\mathrm{EN} 14105$ & $\mathrm{wt} \%$ & $<0.2$ & 0.5 \\
Triglyceride & $\mathrm{EN} 14105$ & $\mathrm{wt} \%$ & $<0.20$ & $\mathrm{n} . \mathrm{d}$. \\
Total glycerol content & $\mathrm{EN} 14105$ & $\mathrm{wt} \%$ & $<0.25$ & 0.21 \\
Water content & $\mathrm{EN} \mathrm{ISO} 12937$ & $\mathrm{ppm}$ & $<500$ & 288 \\
Acid number & $\mathrm{EN} 14104$ & $\mathrm{mg}(\mathrm{KOH}) / \mathrm{g}$ & $<0.5$ & 0.3 \\
Iodine value & $\mathrm{EN} 14111$ & $\mathrm{~g}\left(\mathrm{I}_{2}\right) / 100 \mathrm{~g}$ & $<120$ & 141 \\
Oxidation stability at $11{ }^{\circ} \mathrm{C}$ & $\mathrm{EN} 14112$ & $\mathrm{~h}$ & $>6$ & 0.86 \\
\hline
\end{tabular}

n.d.: not detectable. 
Table 2 Rate constants $(k)$ for consumption of propyl gallate at various temperatures and correlation coefficient $\left(R^{2}\right)$ calculated by assuming the first order rate law

\begin{tabular}{cccc}
\hline Temperature, ${ }^{\circ} \mathrm{C}$ & $k, \mathrm{~h}^{-1}$ & $C_{c r, \mathrm{ppm}}$ & $R^{2}$ \\
\hline 100 & 0.1203 & 101 & 0.9881 \\
105 & 0.1883 & 105 & 0.9942 \\
110 & 0.2739 & 100 & 0.9931 \\
115 & 0.4031 & 103 & 0.9872 \\
120 & 0.6015 & 109 & 0.9917 \\
\hline
\end{tabular}




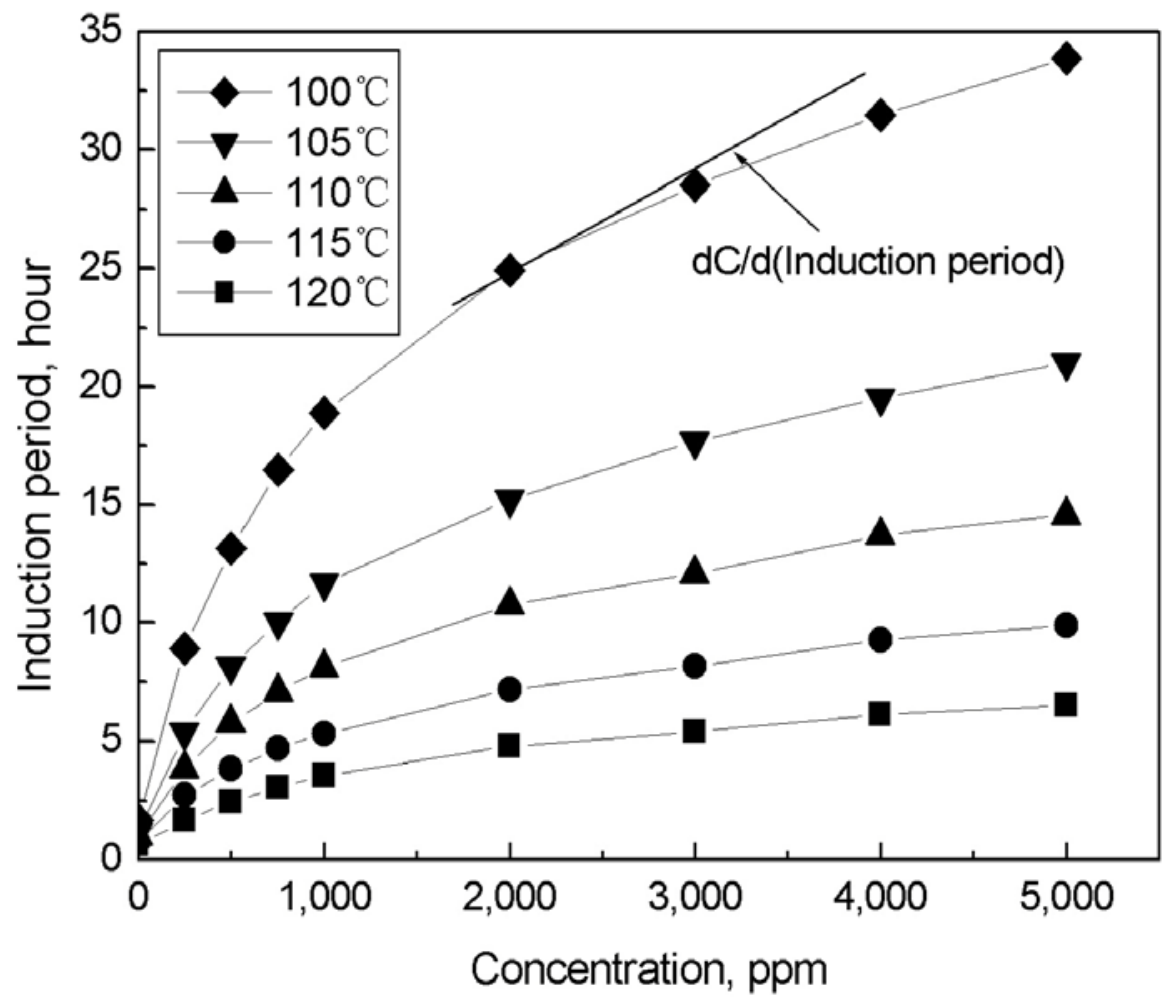

Fig. 1. Influence of propyl gallate concentration on the oxidation stability of safflower biodiesel for the test temperatures as set at 100, 105, 110, 115 and $120^{\circ} \mathrm{C}$. Air flow: 10L/h for $3 g$ biodiesel sample. Changes of induction period with the concentration of propyl gallate (d(induction period) $/ \mathrm{dC}$ ) is the slope of the curve. 


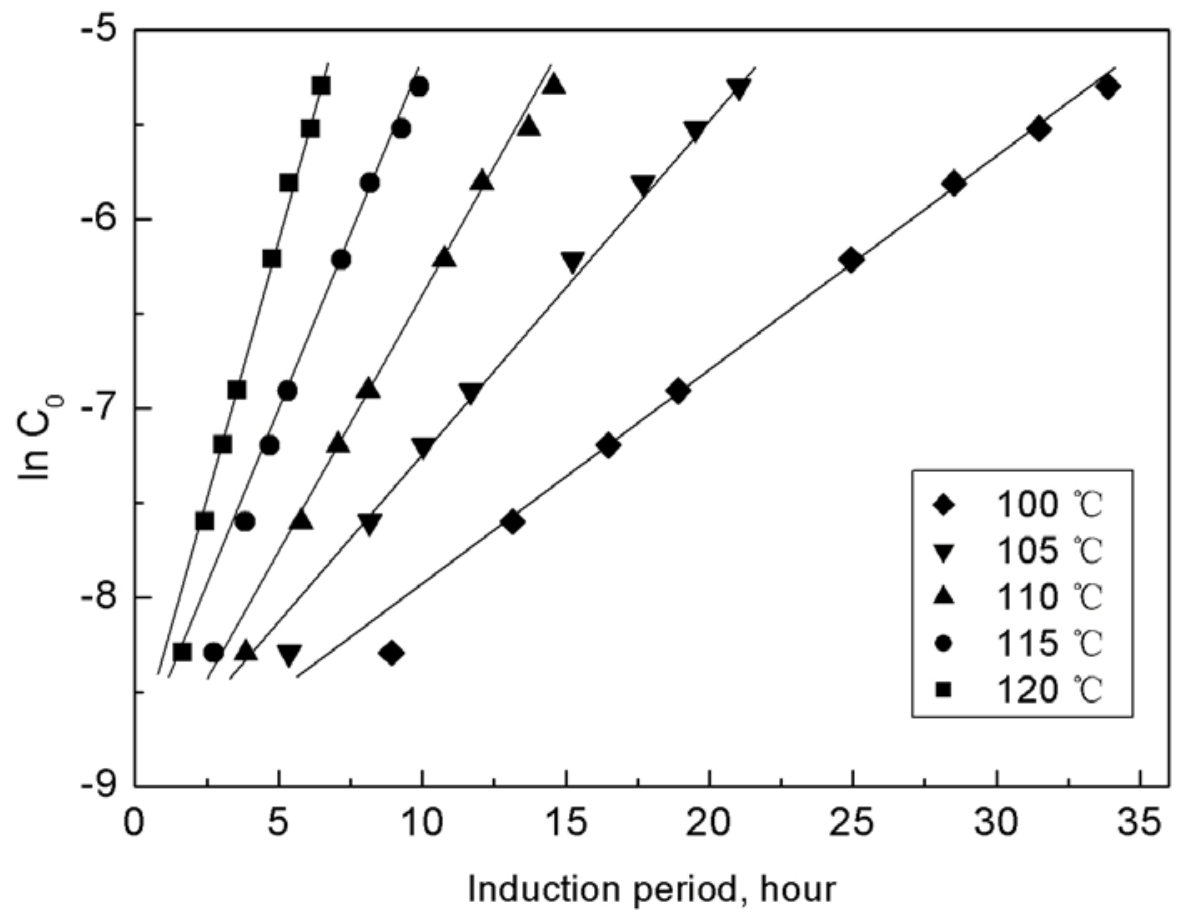

Fig. 2. Dependence of the induction period of safflower biodiesel on the logarithm (ln) of propyl gallate concentration at $100,105,110,115$ and $120^{\circ} \mathrm{C}$. 


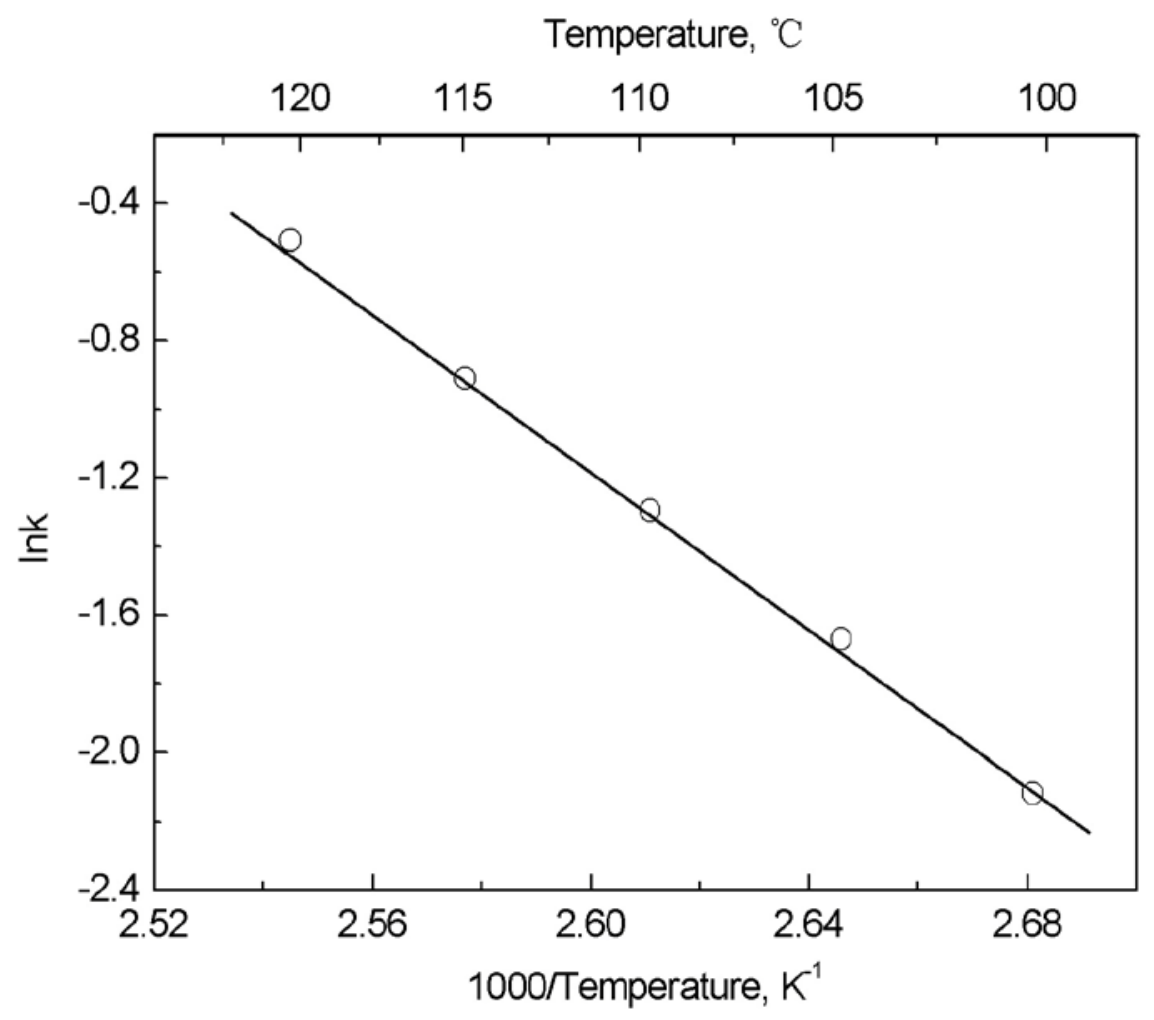

Fig. 3. Temperature dependence of the rate constant of the propyl gallate consumption. 


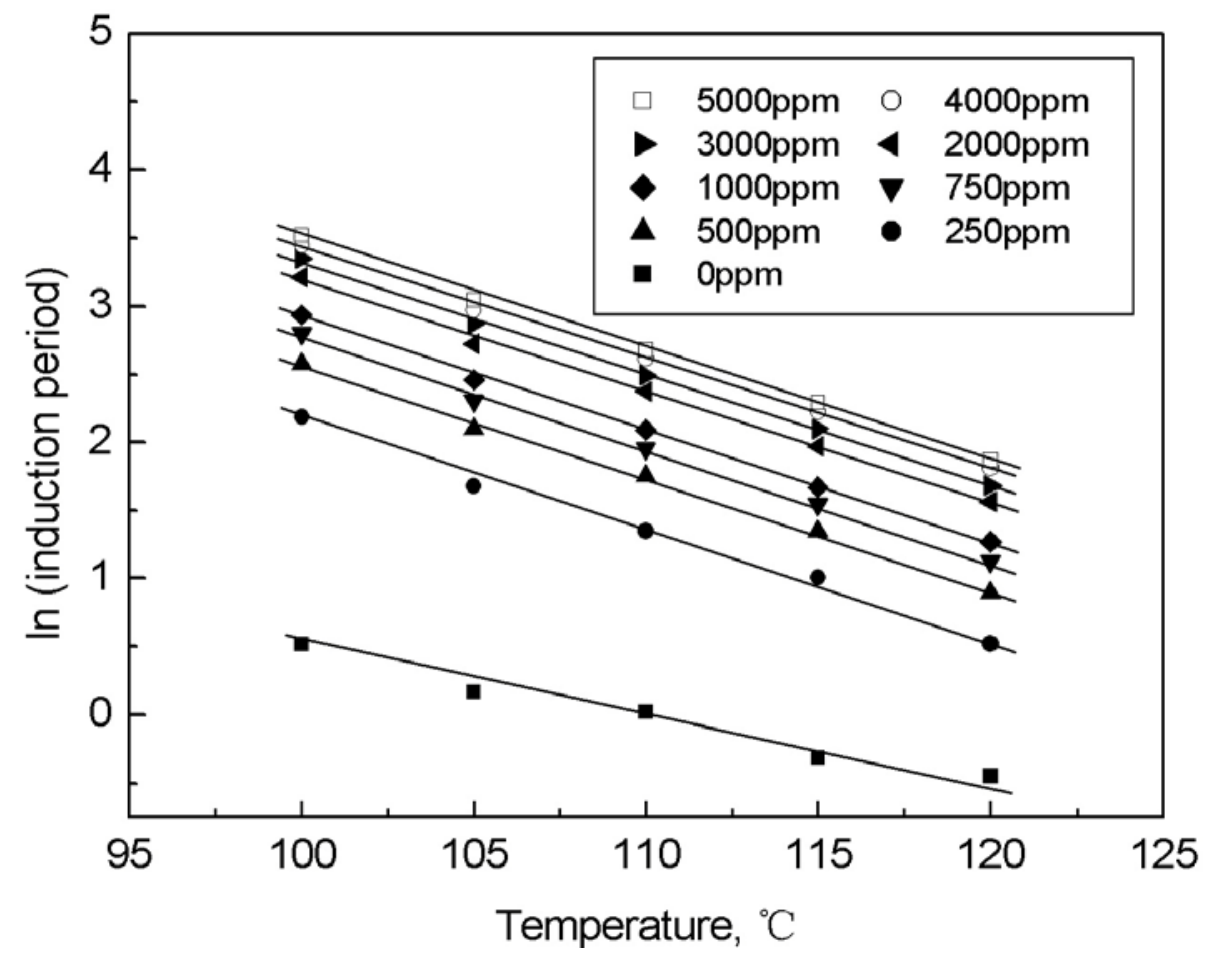

Fig. 4. Logarithm of induction period as a function of temperature for safflower biodiesel stabilized with various concentration of propyl gallate. 


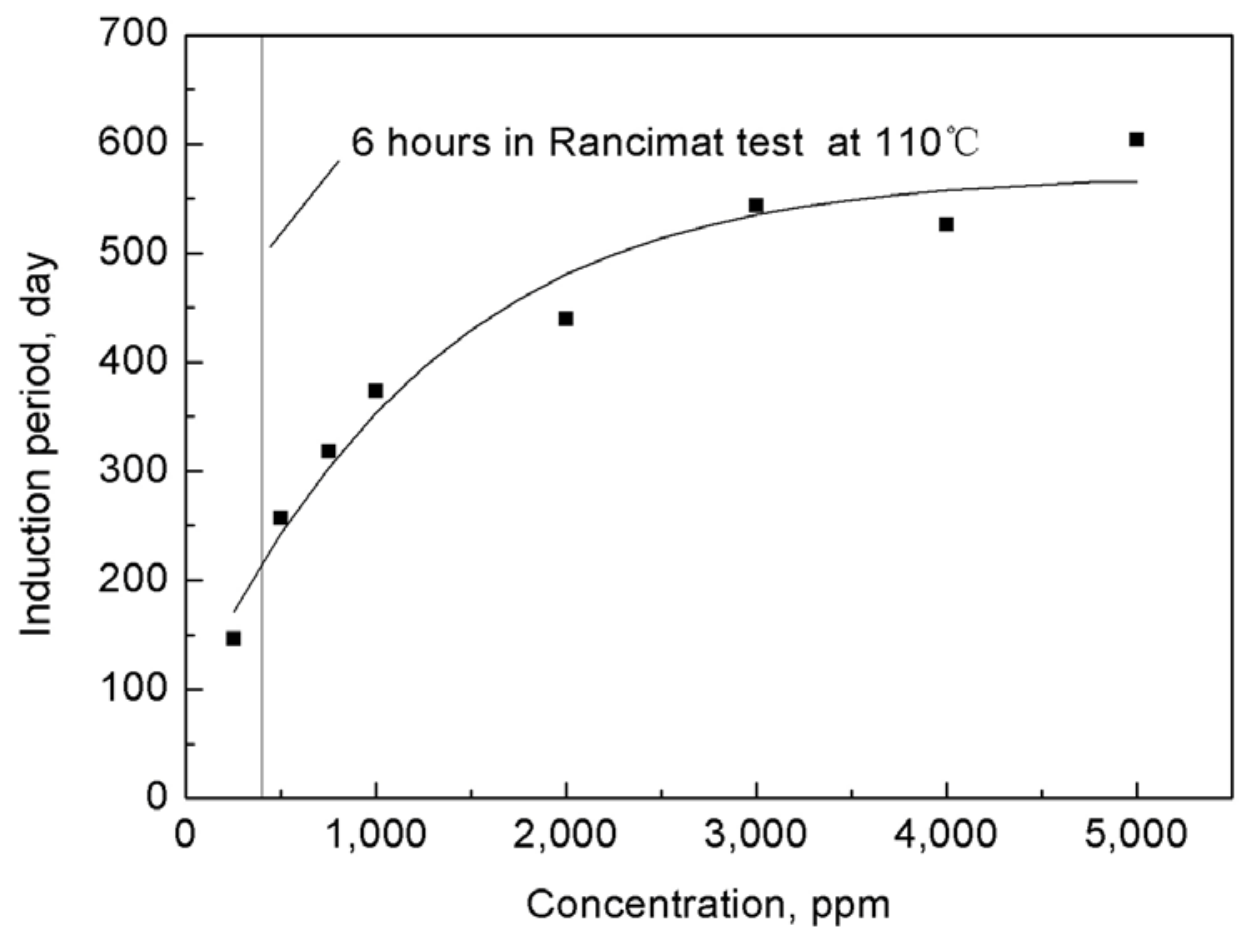

Fig. 5. Induction period of safflower biodiesel at an ambient temperature $\left(25^{\circ} \mathrm{C}\right)$ stabilized with various propyl gallate concentrations as obtained by extrapolating method. 


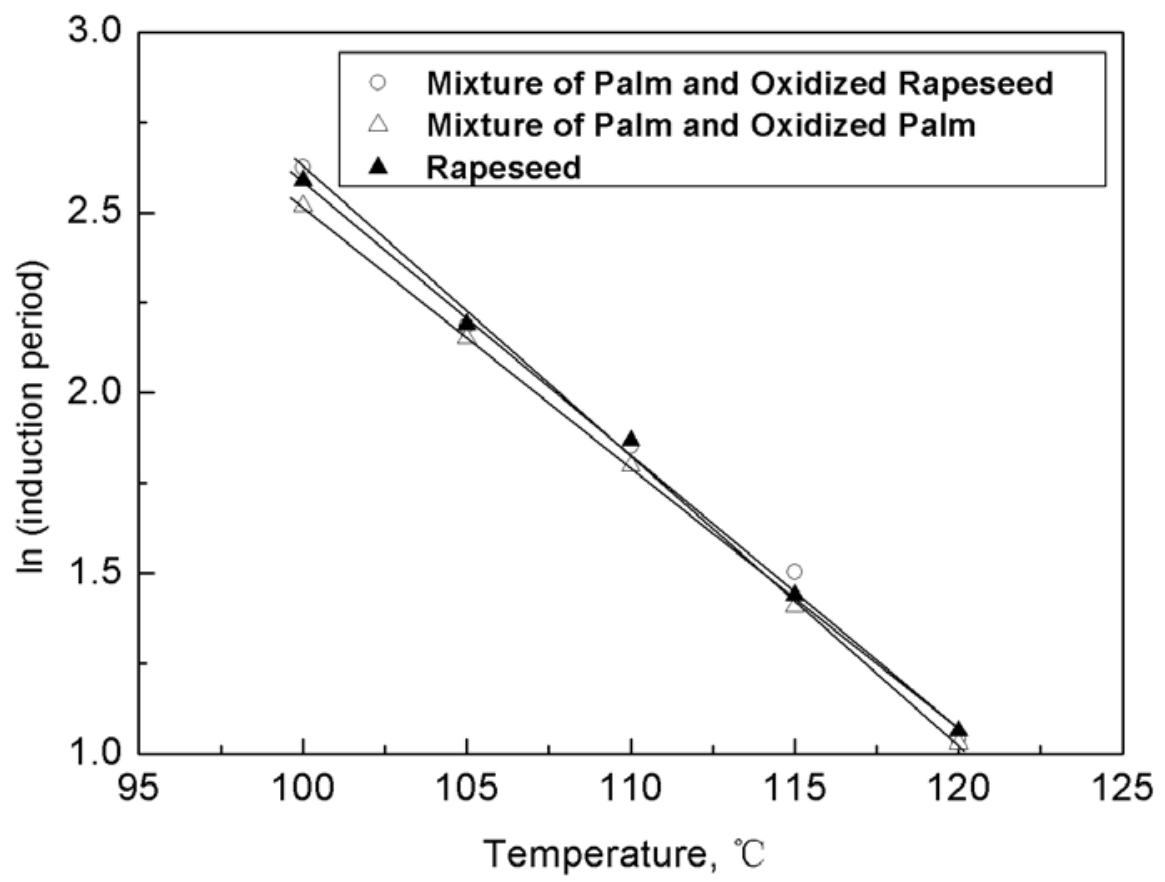

Fig. 6. Logarithm of induction period as a function of temperature for various biodiesel and mixtures of biodiesels, in order to get biodiesel that has the same induction period at $110^{\circ} \mathrm{C}$, the prepared palm and rapeseed biodiesels were stored at $50{ }^{\circ} \mathrm{C}$ for 72 and $36 \mathrm{~h}$ to decrease their induction periods and mixed the oxidized biodiesels with newly prepared palm biodiesels. 